\title{
CONSCIENTIZAÇÃO AMBIENTAL NA EDUCAÇÃO INFANTIL
}

\author{
Daniela da Rosa Schünemann ${ }^{1}$, Marcelo Barcellos da Rosa² \\ ${ }^{1}$ Especialista em Educação Ambiental \\ ${ }^{2}$ Professores do Curso de Especialização em Educação Ambiental da UFSM
}

\begin{abstract}
RESUMO
A Educação Infantil é a primeira etapa da educação escolar. Este artigo teve como objetivo principal inserir a Educação Ambiental na realidade da Educação Infantil, através do desenvolvimento de temáticas com atividades práticas e didáticas, a fim de que a criança tomasse conhecimento dos problemas ambientais de seu bairro e despertasse o seu interesse para as questões ambientais. Para tanto foi realizada uma pesquisa bibliográfica e exploratória desenvolvida entre março a maio de 2010, para verificar a viabilidade desta proposta. A pesquisa foi desenvolvida em uma Escola de Educação Infantil na periferia do município de Cachoeira do Sul. O público alvo foi 80 alunos com idades entre 1 e 5 anos. Foram desenvolvidas cinco temáticas contendo atividades didáticas e práticas referentes ao Meio Ambiente como: plantas, animais, saúde, hábitos de higiene, água, cuidados com o meio ambiente e com o local onde vivem. A proposta mostrou-se ser positiva, pois os alunos demonstraram muito interesse pelos temas abordados. Eles participaram ativamente de todas as atividades desenvolvidas com entusiasmo e dedicação. Com este estudo conclui-se que a Educação Ambiental não só pode, mas deve ser desenvolvida com crianças nesta faixa etária, pois, além das mesmas serem ávidas por novos conhecimentos, os alunos do pré escolar apresentaram a capacidade de sugerir novas atividades, além de discutir e apontar possíveis soluções para os problemas ambientais apresentados.
\end{abstract}

Palavras-chaves: educação infantil; educação ambiental; Cachoeira do Sul; temáticas.

\begin{abstract}
The Preschool education is the first stage of school education. This work aims to introduce the reality of Environmental Education in Early Childhood Education through the development of Thematic with practical activities and teaching, so that the child being aware of environmental problems in their neighborhood and awoke the interest in environmental issues. This project began with a literature search and exploratory conducted between March and May 2010 to verify the feasibility of this proposal. The research was conducted in a School of Early Childhood Education at the periphery of the city of Cachoeira do Sul, south of Brazil. Were considered the opinion of 80 students aged between one and five years. Five Thematic containing educational learning activities and practices concerning the environment such as plants, animals, health, hygiene, water, care for the environment and where they live were worked. The proposal proved to be positive because the students showed much interest in the topic. They participated actively in all the activities with enthusiasm and dedication. With this study it is ended that the Environmental Education not only it can, but it should be developed with children in this age group, because, besides the same ones they be avid for new knowledge, the students of the school Pré presented the capacity to suggest of new activities, besides to discuss and to point possible solutions for the presented environmental problems.
\end{abstract}


Key-words: childhood education; environmental education; Cachoeira do Sul; thematic.

\section{INTRODUÇÃO}

A sociedade mudou, ao longo dos tempos, a visão que tinha sobre o Meio Ambiente, passando a ver o mundo de forma fragmentada, separada por partes, e o homem começou a sentirse um ser superior aos demais, agindo sobre eles, considerando apenas aquilo que é de seu interesse sem preocupar-se com os efeitos e conseqüências que seus atos venham a ocasionar a todo o planeta.

Esta visão fragmentada refletiu-se até mesmo no campo da Educação onde o conhecimento tem ocorrido de forma fracionada, separada em partes, sem procurar apresentar ligações entre as diversas áreas do conhecimento, sem procurar dar ênfase na interdisciplinaridade. Dessa forma o aluno perde a visão do todo vendo apenas partes desconectas tornando-se muito difícil fazer relações entre fatos, causas e possíveis consequências.

Nesse contexto, surgiu a necessidade de modificação desse quadro e a Educação Ambiental enquadra-se nele, pois ela visa à modificação de valores buscando uma melhoria de vida de todos os habitantes do planeta de forma igualitária e sustentável, sempre respeitando a natureza e todos os elementos que a com.

Para realizar essas mudanças de atitudes, nada mais propício do que iniciar pela primeira etapa da vida escolar da criança, ou seja, a Educação Infantil, pois é nessa fase da vida que se desenvolvem as bases do saber, que são fundamentais para a aprendizagem e serão levadas para toda a vida.

A escola é o espaço onde a criança inicia o seu processo de interação com a sociedade, o que nela se faz, se diz e se valoriza, representa um exemplo daquilo que a sociedade aprova. Comportamentos ambientalmente corretos devem ser aprendidos na prática, no cotidiano da vida escolar, contribuindo para formação de cidadãos responsáveis.

A Educação Infantil por sua vez é o começo da vida escolar de todos, onde se aprende conceitos e valores que se leva para toda vida. A criança está sempre disposta a aprender e devemos aproveitar para desenvolver a Educação Ambiental nesta fase de suas vidas, fazendo com que elas entendam e aprendam a valorizar e amar a natureza e todos seus elementos formadores, pois, se desde pequenos forem conscientes de suas responsabilidades, certamente no futuro serão adultos conscientes de seu papel no mundo onde vivem.

Nesse contexto nada mais propício e importante do que iniciar um trabalho de conscientização ambiental através da inserção da Educação Ambiental no cotidiano de uma escola de Educação Infantil, a fim de que as crianças de hoje, no futuro, façam parte de sociedades mais justas onde os cidadãos respeitam a si próprios, os seus semelhantes e a todas as formas de vida existentes no planeta.

\section{OBJETIVOS}

\section{Objetivo Geral}

Despertar, no aluno da Educação Infantil, o interesse pelos temas relacionados à questão ambiental.

\section{Objetivos Específicos}


1. Descobrir, juntamente com os alunos, problemas ambientais que existem no meio onde vivem e discutir algumas das possíveis soluções para tentar solucioná-los.

2. Desenvolver com os alunos atividades práticas como: passeios pelo bairro onde os alunos residem; plantio de mudas de árvores frutíferas ao redor da escola; limpeza do pátio da escola; confecção de maquetes e objetos utilizando materiais recicláveis; visita e entrevista a pais de alunos que trabalham com a reciclagem de materiais, entre outros, proporcionando aos alunos mais conhecimento a respeito da comunidade onde vivem, ajudando-os a descobrirem novas formas de tornarem esse local, um lugar melhor para se viver.

3. Possibilitar através do desenvolvimento de atividades didáticas como: confecção de murais e cartazes; participação na hora do conto; criação de histórias; criação de desenhos livres sobre temas abordados; confecção de móbile, entre outras, mais conhecimento sobre o meio ambiente e formas de como ajudar na sua preservação.

4. Colocar em prática na escola alguns projetos relacionados à Educação Ambiental.

\section{METODOLOGIA}

Esta pesquisa foi desenvolvida através de uma pesquisa com abordagem qualitativa onde realizou- se um estudo de caso, com alunos da Educação Infantil da Escola Municipal de Educação Infantil Sagrado Coração de Jesus.

\section{Características da instituição onde foi desenvolvida a pesquisa}

A pesquisa foi desenvolvida na Escola Municipal de Educação Infantil Sagrado Coração de Jesus, no Bairro Promorar. Localizada no Bairro há 17 anos, atende 80 alunos com idade de 1 ano a 5 anos, 30 desses alunos ficam na escola em turno integral e 50 alunos são divididos entre os turnos da manhã e da tarde.

\section{Público Alvo}

O público alvo da pesquisa foram os 80 alunos da Escola Municipal de Educação Infantil Sagrado Coração de Jesus, sendo 22 alunos da turma de PRE-A com 4 anos, 24 de Pré-B com 5 anos, 20 do Maternal com 3 anos e 16 do Berçário com idade de 1 a 2 anos .

Os alunos são filhos de moradores do Bairro Promorar e Habitar Brasil, e em sua maioria possuem pouco poder aquisitivo. A maioria dos pais trabalha de forma autônoma, sendo que grande parte trabalha com reciclagem de materiais.

\section{Aplicação da pesquisa}

A pesquisa foi desenvolvida nos meses de março a maio de 2010, através de temáticas trabalhadas numa série de atividades desenvolvidas com os alunos, tendo como objetivo principal, demonstrar a viabilidade de inserir a Educação Ambiental na Educação Infantil, procurando o interesse dos alunos pelos temas relacionados à questão ambiental.

As temáticas tiveram, em média, duração de dez a quinze dias, sendo que as atividades variavam, de acordo com a faixa etária dos alunos. Procuraram abordar os seguintes temas: importância das plantas e animais em nossa vida; a forma como devemos tratar o lixo e os problemas gerados por ele; os principais problemas ambientais existentes no bairro onde os alunos vivem; e as necessidades do ser humano: abrigo, saúde e alimentação.

Títulos das temáticas desenvolvidas:

- Primeira temática: a importância das plantas em nossa vida; 
- Segunda temática: passeio pelo bairro, identificando a presença do lixo;

- Terceira temática: reciclagem de materiais;

- Quarta temática: confecção de bichinhos com garrafas PET (sustentabilidade e Reciclagem);

- Quinta temática: higiene e saúde.

As temáticas partiram sempre da necessidade dos alunos: suas curiosidades e informações; assuntos relevantes naquele momento e de temas relevantes também para a escola. Tinham sempre objetivos específicos da área a ser trabalhada e os da escola para aquela determinada faixa etária, conforme estrutura apresentada no quadro baixo.

\begin{tabular}{|l|l|}
\hline Tema & $\begin{array}{l}\text { Sempre decidido entre professor e alunos e de relevância para } \\
\text { ambos, sendo que o professor deve ter conhecimento prévio da } \\
\text { temática a ser trabalhada. }\end{array}$ \\
\hline Justificativa & $\begin{array}{l}\text { Na justificativa, sempre, ser apresentada a importância de se } \\
\text { trabalhar esse assunto naquele dado momento. }\end{array}$ \\
\hline Tempo de duração & $\begin{array}{l}\text { Nesse momento é feita uma previsão de quando se iniciara e } \\
\text { quando terminará o projeto. A duração é sempre flexível. }\end{array}$ \\
\hline Objetivos & $\begin{array}{l}\text { Nos objetivos é exposto aquilo que se pretende alcançar ao final } \\
\text { do projeto. Contém o objetivo geral e os específicos que dizem } \\
\text { respeito ao tema ora trabalhado e os sugeridos pela proposta } \\
\text { pedagógica da escola. }\end{array}$ \\
\hline Atividades e materiais & $\begin{array}{l}\text { Nesse item são selecionadas as atividades que serão } \\
\text { desenvolvidas, a fim de se alcançar os objetivos propostos, bem } \\
\text { como os materiais que serão utilizados. }\end{array}$ \\
\hline Culminância & $\begin{array}{l}\text { A culminância é o produto final do projeto onde são apresentados } \\
\text { os pontos positivos e os negativos e o que deveria ser melhorado. } \\
\text { Nesse momento verifica-se a viabilidade do projeto e se os } \\
\text { objetivos foram alcançados. }\end{array}$ \\
\hline
\end{tabular}

Quadro A: Estrutura básica das temáticas

As atividades desenvolvidas eram práticas e didáticas, sempre baseadas em muita observação e levando sempre em consideração as experiências anteriores dos alunos e sua faixa etária. Nem todos os alunos participaram de todas as atividades desenvolvidas devido estarem em faixas etárias diferentes.

\section{RESULTADOS E DISCUSSÃO}

Durante o trabalho desenvolvido pode-se verificar que os alunos mostraram-se sempre dispostos e curiosos a participar das atividades. As atividades práticas e didáticas foram desenvolvidas integradas a temáticas, que tiveram início na segunda quinzena de março.

Para o melhor entendimento dos resultados será feito um comentário sobre as temáticas desenvolvidas, a fim de tornar mais fácil a compreensão dos resultados obtidos.

\section{- Primeira temática}

A primeira temática desenvolvida teve como tema a importância das plantas em nossa vida. Partiu do interesse dos alunos pelo tema, devido a conversas em aula sobre o inicio do outono, tido como estação das frutas. 
O trabalho sobre as plantas é de grande importância e faz parte do nosso dia a dia. As crianças devem, desde pequenas, ter consciência da sua importância para nossa vida e de como devemos cuidar e preservar este bem tão valioso, sendo que esse foi o principal objetivo desse trabalho e teve duração de dez dias.

Por considerar este tema de grande importância e aproveitando o interesse dos alunos, foi realizado um passeio para verificar quais espécies frutíferas eram encontradas no bairro, explorando as árvores, suas características e sua importância. Se elas eram todas iguais, quais as diferenças e qual o motivo destas diferenças.

A partir daí foram desenvolvidas várias atividades sobre o tema, destacando a importância de todas as plantas para o Meio Ambiente, concluindo que sem elas não existiria vida no planeta.

Os alunos desenharam, em cartazes, vários tipos de plantas. Fizeram o desenho de árvores, utilizando para fazer a copa, folhas que estavam caídas no pátio da escola. Foram apresentadas gravuras, fora de ordem, de uma menina plantando e cuidando de uma planta e solicitado aos alunos que as colocassem na ordem correta em que aconteceram os fatos e fizessem uma história comentando a atitude da menina.

As crianças também puderam apreciar uma história infantil: "A margarida Friorenta" que falava das plantas e da forma como devemos cuidá-las.

Depois foram convidados a ajudarem a plantar algumas mudas de árvores frutíferas no pátio da escola, para que no futuro produzam frutos, que poderão ser saboreados por eles mesmos e sombra para que eles possam brincar no pátio, nos dias quentes. Os alunos maiores (turmas de pré $\mathrm{A}$ e B) foram encarregados de protegerem as plantinhas, cuidando para que elas tenham garantido tudo que é necessário para que ocorra o pleno desenvolvimento das mesmas.

Assistiram também a um filme infantil intitulado: "A invasão das formigas" que relata, através de um desenho, como um grupo de formigas cortadeiras estava destruindo com todas as plantas e conseqüentemente com toda a floresta. Dessa forma mostrou-se que acontece o mesmo com o meio ambiente, se nós, seres humanos, também não cuidarmos da nossa flora. Acabaremos com todo o planeta.

Alguns alunos também apresentaram, para os demais colegas, uma peça teatral intitulada "Frutinhas amigas" nesta peça foram exploradas a importância das frutas para nossa vida e como elas são importantes para o pleno funcionamento do nosso corpo.

Durante essa temática, foram desenvolvidos outros trabalhos sendo que culminou com uma atividade, onde cada aluno trouxe um tipo de fruta. Com esse material foi feita uma salada de fruta e ao final todos lancharam juntos em sala de aula. Durante as atividades os alunos comentavam os seus alimentos preferidos (frutas e verduras) e a quais eles tinham acesso em suas casas.

Este trabalho proporcionou às crianças um contato direto com as plantas, de forma que elas puderam observar a importância de preservarmos todo tipo de flora, por mais simples que estas nos pareçam, sendo que eles demonstraram muito interesse e ficaram motivados com o projeto.

\section{- Segundo temática}

$\mathrm{Na}$ segunda temática, os alunos foram convidados a darem uma saída pelo bairro. Nesse passeio visualizamos muito lixo espalhado em uma área de terrenos baldios, nas ruas, e numa sanga que atravessa o bairro. Nessa sanga, além do lixo, há problemas de erosão devido às árvores da mata ciliar terem sido derrubadas para a construção de casas. Em todos os momentos os alunos foram instigados a perceber o que ocorreu, para que tais locais ficassem desta forma. Durante o passeio, alguns alunos chegaram a citar nomes de pessoas do próprio bairro que eles visualizam colocando lixo nesses locais e que cortaram algumas árvores para fazer aumento nas casas. 
A partir daí iniciamos um projeto que teve como tema: Nossa escola de mãos dadas com a natureza e com o meio onde vivemos. Teve duração de quinze dias.

Esse trabalho veio de encontro com um dos objetivos dessa proposta, que se propõem a levar os alunos, a perceberem os problemas ambientais que existem no local onde vivem, o que os causou e formularem sugestões possíveis para solucioná-los, tornando-se plenamente justificável e de relevante importância de ser desenvolvido com os alunos

Durante essa temática foram desenvolvidas algumas atividades como por ex: desenho do bairro mostrando como ele se apresenta e como eles gostariam que ele fosse; confecção de um livrinho onde os alunos apresentaram os problemas ambientais locais que visualizaram; conversação orientada para discutir os problemas e formular possíveis soluções.

Os alunos também ouviram uma história sobre os índios e sobre a forma como eles cuidavam do Meio Ambiente, como eles conviviam de forma harmônica com a natureza, levando os alunos a refletirem de que nós também podemos e devemos viver assim, sem agredi-la.

Depois de muito debater o tema, o projeto culminou com uma sugestão dos alunos de fazer algo para melhorar o que vimos. Juntos, resolvemos fazer a limpeza do pátio e da rua em frente à escola. Foram confeccionados cartazes mostrando como eles gostariam de ver a sanga que foi visitada. Os cartazes foram colocados no mural da escola, onde todos puderam visualizar suas sugestões e concluímos com uma proposta de realizarmos atividades com os materiais recicláveis jogados fora, nos locais inadequados.

Este trabalho teve um tempo de duração maior do que o esperado, tamanho o incentivo dos alunos. Ao finalizar esta temática, decidimos que uma vez por semana faríamos uma limpeza no pátio da escola, mantendo-a sempre limpa, conseguindo desta forma não só detectar os problemas e propor soluções, mas ir além, realizando ações para diminuir o problema, inclusive incentivando outras pessoas a tomarem consciência dos problemas existentes e de que forma poderemos juntos, solucioná-los.

\section{- Terceira temática}

A partir da problemática levantada anteriormente que tratou dos problemas ambientais locais, iniciou-se a terceira temática que teve como tema a reciclagem dos materiais encontrados no bairro, atirados em locais impróprios, em ruas, terrenos e dentro de uma sanga. Essa temática durou cerca de dez dias.

O principal objetivo desse trabalho foi destacar a importância da reciclagem de materiais colaborando com a preservação do Meio Ambiente, tendo em vista que muito lixo é jogado na natureza, inclusive onde os alunos residem, causando problemas a todos. Por esse motivo, considerou-se importante trabalhar esse tema apresentando várias sugestões de reaproveitamento que podem ser realizadas no dia a dia na escola e em suas próprias casas, destacando sempre a importância das pessoas que trabalham com a reciclagem.

Após uma conversa realizada com os alunos, resolvemos reciclar alguns materiais como garrafas pet, papelões, folhas de jornal, revistas e folhas de oficio já utilizadas dos dois lados.

Em um primeiro momento, juntamos várias garrafas que estavam em um terreno baldio, localizado perto da escola. Para realizar esta atividade, os participantes utilizaram luvas cirúrgicas para evitar o contato direto com os materiais. Logo levamos o material recolhido para a escola e realizamos a limpeza dos mesmos.

As garrafas pet foram utilizadas para confeccionar uma cestinha, depois cada aluno plantou uma muda de flor, para ser o presente para as mães no seu dia. A parte superior da garrafa foi 
utilizada para fazer um brinquedo chamado bilboquê que serviu para os alunos brincarem na escola e posteriormente levaram para casa, no final da aula.

Também fizemos uma visita a dois pais de alunos que trabalham com a reciclagem de materiais. Os alunos observaram os materiais que podem ser reciclados e fizeram pergunta sobre esta atividade que ajuda muito na preservação do Meio Ambiente e que atualmente é responsável pelo sustento de muitas famílias, inclusive a de muitos alunos da escola, pois, cerca de quinze pais de alunos trabalham com a reciclagem de materiais.

Outra atividade desenvolvida foi o reaproveitamento de jornais velhos. Onde cada aluno recebeu uma folha de jornal e foram realizadas várias atividades. Ao final eles rasgaram o jornal em pedacinhos bem pequenos. O jornal picado foi misturado à água e triturado no liquidificador e posteriormente escorrido. Logo foi misturado cola e tinta de cores variadas tornando-se massa de modelar que eles usaram para brincar.

Com as folhas de oficio, foi realizado o mesmo processo. Elas foram picadas, trituradas e colocadas em uma peneira e depois prensadas virando uma folha de papel reciclável. Depois de seco cada aluno escreveu seu nome em uma parte do papel e fez um cartão para a mãe.

\section{- Quarta temática}

A quarta temática foi desenvolvido como uma continuação da anterior, a partir de uma atividade onde cada aluno trouxe uma garrafa pet e foram confeccionados bichinhos decorativos.

A partir desta atividade foi realizado um trabalho que teve como tema: os animais explorando as características dos animais e sua importância em nossa vida. Este trabalho durou dez dias e procurou ressaltar a importância dos animais em nossa vida. Como devemos tratá-los, os cuidados que devemos ter explorando suas diferenças e características. A primeira atividade realizada foi um passeio pelo bairro para observar os animais existentes no local.

Olhamos também vários livrinhos infantis que contavam histórias sobre animais. Os alunos olharam e logo cada um contou uma história inventada a partir da observação do livro. Também fizeram desenho e pintura de vários animais e cantamos músicas que falavam dos animais, sendo que os alunos sugeriam a música e imitavam os animais.

Os alunos também assistiram ao filme infantil "Os sem floresta" essa história explorou a questão dos animais que perdem seu habitat e vão parar na cidade dividindo o mesmo espaço com os seres humanos.

Os alunos do Maternal e Pré A e B também confeccionaram um livrinho sobre seu animal de estimação.

Após varias atividades realizadas, concluímos o projeto com um passeio ao Zoológico Municipal, onde todos puderam saber um pouco mais sobre os animais, aprendendo a respeitá-los e compreendendo que cada um tem sua importância para o equilíbrio do Meio Ambiente. Durante o passeio, os alunos comentaram as diferenças e semelhanças existentes entre os mesmos, observando as características externas, hábitos alimentares e habitat.

Através desse trabalho, as crianças puderam perceber que os animais e as plantas são seres vivos como nós e que merecem nosso respeito, cuidado e carinho, pois são responsáveis pela manutenção de todo ecossistema e fundamentais para manter o equilíbrio do planeta.

\section{- Quinta temática}

A quinta temática surgiu a partir de um projeto realizado nas escolas do município onde os alunos de odontologia da ULBRA, realizam o tratamento dentário das crianças na própria escola. Levando em consideração o interesse dos alunos, realizarmos um trabalho que tratava das necessidades básicas do ser humano: saúde, alimentação e abrigo. 


\section{Monografias Ambientais}

(Revista Eletrônica do PPGEAmb-CCR/UFSM) ISSN:

Esta temática foi muito importante, pois os alunos sentiram o quanto é importante cuidarmos da nossa saúde e do local onde vivemos para temos uma vida saudável. Foram mais quinze dias nessa etapa.

Durante o projeto foram realizadas várias atividades como: conversação orientada sobre os alimentos que não podem faltar em nossa alimentação diária e preparação de uma sopa contendo alguns destes alimentos; os alunos assistiram a uma peça de teatro apresentada por alguns alunos, intitulada "Frutinhas Amigas" e a um filme sobre a importância de cuidarmos de nossos dentes e de hábitos de higiene; também confeccionaram uma maquete onde cada aluno fez sua casa, utilizando caixa de papelão; também fizemos uma visita ao posto de saúde para conversar sobre formas de prevenir doenças.

Durante este projeto, também realizamos atividades que tratavam da importância da água em nossa vida e para a manutenção de todo o planeta.

O projeto culminou com a exposição das maquetes e com uma peça de teatro, onde os alunos mostraram os mais diversos usos da água e a importância dos hábitos de higiene como forma de prevenir doenças inclusive gripe H1N1 que voltou a assustar com a chegada do inverno. Tanto a exposição como a apresentação foi realizada na presença dos pais.

Após o desenvolvimento das temáticas pode-se constatar que elas foram muito importantes, pois se observou que os alunos demonstraram muito interesse e envolvimento durante a realização das mesmas participando ativamente de todas as atividades, dando sugestões tais como: a escolha do tema que foram trabalhados, que na maioria das vezes eles mesmos levantaram a problemática para que fossem desenvolvidos os projetos, despertando-os, dessa forma, para questões importantes relacionadas ao Meio Ambiente.

Os alunos também tiveram a oportunidade de detectarem alguns problemas ambientais que ocorrem no meio onde vivem como a poluição e desmatamento da mata ciliar da sanga que atravessa o bairro, o problema do lixo atirado nas ruas em terrenos baldios e no pátio da própria escola. Chegaram a conclusão de que tais problemas são gerados na maioria das vezes, por pessoas da própria comunidade mas que afetam a todos direta ou indiretamente e principalmente foi lhes dado a chance de darem sugestões de como solucionar ou minimizar tais problemas.

Outro fator muito importante foi o envolvimento dos demais professores da escola no decorrer das temáticas mesmo não sendo esse um dos objetivos da pesquisa.

As crianças, nessa idade, estão em pleno desenvolvimento de suas capacidades. Devemos assegurar e estimular esse desenvolvimento e é fundamental que, também sejam trabalhados, na escola, valores que são tidos como positivos pela sociedade. Ainda é importante destacar que as escolas de Educação Infantil devem assegurar, que todos os direitos da criança estabelecidos pelo Estatuto da Criança e do Adolescente sejam respeitados, sendo que o cuidar e o educar devem sempre andar juntos, mas nunca esquecendo que é nessa fase da vida onde os valores e atitudes que são transmitidos serão levados e refletirão por toda a vida.

\section{CONCLUSÃO}

Pode-se concluir que o desenvolvimento da Educação Ambiental em uma escola de Educação Infantil, possibilitou aos alunos maior conhecimento, reflexão e discussão acerca dos assuntos ligados a questões ambientais, fazendo com que estes despertassem para esses temas, tornando-os mais atentos e conscientes a fim de que assumam uma postura critica frente essas questões. 
Os alunos conseguiram descobrir alguns dos problemas ambientais que ocorrem no bairro onde vivem e o mais importante: os alunos de Pré escola conseguiram dar sugestões para tentar resolver, diminuir e prevenir tais problemas. Não só sugeriram, mas realizaram ações concretas para tanto.

As temáticas que foram desenvolvidas durante esse trabalho, apresentaram-se como uma forma positiva de trabalhar tais questões de forma interdisciplinar, pois como são flexíveis, proporcionaram, aos alunos, abertura para que pudessem sugerir os temas e opinar sobre as atividades, inclusive no aspecto relacionado ao tempo de duração das mesmas, proporcionando-lhes a oportunidade de exporem suas necessidades e conhecimentos já adquiridos, contemplando sempre os objetivos que deveriam ser trabalhados.

As atividades práticas e as didáticas também se apresentaram como ferramentas fundamentais para abordar os temas trabalhados e alcançar os objetivos previstos.

Os alunos demonstraram especial interesse pelas atividades práticas sendo que elas serviram como um incentivo para a realização das demais atividades.

É possível afirmar que é viável e importante o desenvolvimento desse tipo de trabalho, tendo em vista que os alunos, público alvo da pesquisa, demonstraram curiosidade, interesse e muita vontade de aprender e ampliar seus conhecimentos. Além disso, nessa etapa da vida escolar, a escola e as famílias estão muito mais ligadas. Trabalhando com os alunos, consegue se alcançar as famílias e dessa forma o resultado é ainda mais positivo.

Desse modo, considero que todos os objetivos dessa proposta de trabalho foram plenamente alcançados, chegando ao seu final com uma perspectiva de continuação, já que durante uma formação continuada que ocorreu na escola, no inicio de julho de 2010, optou-se por continuar trabalhando a Educação Ambiental na escola no decorrer deste ano. Os objetivos começarão a fazer parte da proposta pedagógica da escola, pretendendo-se ampliar esse trabalho, visando desenvolver atividades com os pais dos alunos a fim de que no futuro possam ocorrer significativas mudanças socioambientais nessa comunidade.

Por fim, pode-se dizer que se conseguiu, com êxito, despertar nos alunos da Educação Infantil, o interesse pelos temas relacionados à questão ambiental através da inserção da Educação Ambiental na Educação Infantil.

\section{REFERÊNCIAS BIBLIOGRÁFICAS}

AMORIN in SERIE FUNDO DO MILÊNIO PARA A PRIMEIRA INFÂNCIA. Cadernos Pedagógicos-3Legislação, Políticas e Influencias Pedagógicas na Educação Infantil. Brasília, UNESCO, Banco Mundial, Fundação Mauricio Sirots K, Sobrinho 2005.

\section{BAPTISTA, Wanessa. Educação ambiental através da ludicidade: Um relato de experiência}

BRASIL. Ministério da Educação e do Desporto. Secretaria de Educação Fundamental. Referencial Curricular Nacional para a Educação Infantil. volume 3, Brasília. MEC/SEF 1998.

CAMPOS in SERIE FUNDO DO MILÊNIO PARA A PRIMEIRA INFÂNCIA. Cadernos Pedagógicos-3Legislação, Políticas e Influencias Pedagógicas na Educação Infantil. Brasília, UNESCO, Banco Mundial, Fundação Mauricio Sirots K, Sobrinho 2005. 
CAMPOS in SERIE FUNDO DO MILÊNIO PARA A PRIMEIRA INFÂNCIA. Cadernos Pedagógicos-1Olhares das Ciências sobre Crianças. Brasília, UNESCO, Banco Mundial, Fundação Mauricio Sirots K, Sobrinho 2005.

CASTRO in SERIE FUNDO DO MILÊNIO PARA A PRIMEIRA INFÂNCIA. Cadernos Pedagógicos-1- Olhares das Ciências sobre Crianças. Brasília, UNESCO, Banco Mundial, Fundação Mauricio Sirots K, Sobrinho 2005.

CUBERES; Maria Tereza Gonzáles. Entre as Fraldas e as Letras. Contribuições á educação infantil, 2o ed , ED Artimed 2002 trad. Beatriz,Afonso Neves- Porto Alegre. ED Artes Medicas 1997.

DIDONET, V. Creche a que Veio... Para Onde vai. V.18, no 73, 93 p. 1997.

DOHME, Vânia. Atividades Lúdicas na educação: o caminho de tijolos amarelos do aprendizado. 4a edição. Petrópolis, ed. Vozes, 2008.

LOPES in SERIE FUNDO DO MILÊNIO PARA A PRIMEIRA INFÂNCIA. Cadernos Pedagógicos-2- A Criança Descobrindo e Agindo sobre o Mundo. Brasília, UNESCO, Banco Mundial, Fundação Mauricio Sirots K, Sobrinho 2005.

LOPES in SERIE FUNDO DO MILÊNIO PARA A PRIMEIRA INFÂNCIA. Cadernos Pedagógicos-4- 0 cotidiano no Centro de Educação Infantil. Brasília, UNESCO, Banco Mundial, Fundação Mauricio Sirots K, Sobradinho 2005.

LOPES in SERIE FUNDO DO MILÊNIO PARA A PRIMEIRA INFÂNCIA. Cadernos Pedagógicos-1- Olhares das Ciências sobre Crianças. Brasília, UNESCO, Banco Mundial, Fundação Mauricio Sirots K, Sobrinho 2005.

LÜCK, Heloísa. Pedagogia Interdisciplinar: fundamentos teórico-metodológicos. Petrópolis. Ed. Vozes, 1994.

LÜDKE, ANDRÉ. A pesquisa em Educação: abordagens qualitativas. São Paulo: EPU, 1986.

MININNI, Nana Medina e Santos; CONCEIÇÃO, Elizabeth da. Educação Ambiental para o Século XXI \& A Construção do Conhecimento: suas implicações na Educação Ambiental. Brasília, IBAMA, 1997.

Ministério da Educação e do Desporto. Secretaria de Educação Fundamental. Referencial Curricular Nacional para a Educação Infantil, volume 1. Brasília. MEC/SEF. 1998.

MORIN; Edgar. Ecologia e revolução -1979.

MOUSINHO, Patrícia. Educação Ambiental e sua interdisciplinaridade. Universidade Federal de Juiz de Fora, 2003. 


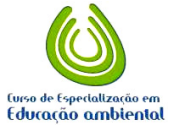

REMOA

\section{Monografias Ambientais}

(Revista Eletrônica do PPGEAmb-CCR/UFSM) ISSN:

Ministério da Educação, Secretaria da Educação Fundamental PARÂMETROS CURRICULARES NACIONAIS. Meio Ambiente e Saúde, 3oed. ED Brasília 2001.

PEREIRA, Antônio Batista. Aprendendo Ecologia através da Educação Ambiental, Porto Alegre ed. Sagra DC. LUZZATTO, 1998

PIAGET, Jean. A linguagem e o pensamento da criança. Rio de Janeiro: Fundo de cultura, 1973.

PRODANON, CC; Freitas; EC. Metodologia do trabalho Cientifico: método e técnicas da pesquisa e do trabalho acadêmico. Novo Hamburgo: Feevale, 2009.

REIGOTA, Marcos. Meio Ambiente e Representação Social. 2a ed. São Paulo. Ed. Cortez, vol. 41. Coleção Questões da Nossa Época,1997.

ROSA, Marcelo Barcellos. Formação do Pensamento Crítico em Educação Ambiental. DCG - UFSM

ROSENAU; Luciana dos Santos. Pesquisa e pratica profissional. Curitiba ed, BPEX 2008.

LOPES in SERIE FUNDO DO MILÊNIO PARA A PRIMEIRA INFÂNCIA. Cadernos Pedagógicos-1- Olhares das Ciências sobre Crianças. Brasília, UNESCO, Banco Mundial, Fundação Mauricio Sirots K, Sobrinho 2005.

SILVA in SERIE FUNDO DO MILÊNIO PARA A PRIMEIRA INFÂNCIA. Cadernos Pedagógicos-2- A Criança Descobrindo e Agindo sobre o Mundo. Brasília, UNESCO, Banco Mundial, Fundação Mauricio Sirots K, Sobrinho 2005.

LOPES in SERIE FUNDO DO MILÊNIO PARA A PRIMEIRA INFÂNCIA. Cadernos Pedagógicos-2- A Criança Descobrindo e Agindo sobre o Mundo. Brasília, UNESCO, Banco Mundial, Fundação Mauricio Sirots K, Sobrinho 2005.

LOPES in SERIE FUNDO DO MILÊNIO PARA A PRIMEIRA INFÂNCIA. Cadernos Pedagógicos-4- 0 cotidiano no Centro de Educação Infantil. Brasília, UNESCO, Banco Mundial, Fundação Mauricio Sirots K, Sobradinho 2005.

ROSEMBERG in SIMPÓSIO EDUCAÇÃO INFANTIL: Construindo o Presente; Anais. Brasília ED, UNESCO, Brasil 2003.

VAGATON in SIMPÓSIO EDUCAÇÃO INFANTIL: Construindo o Presente; Anais. Brasília ED, UNESCO, Brasil 2003.

VERGARA; Silvia Constan. Projetos e relatórios de pesquisa em administração. São Paulo. Editora Atlas 2000. 